\title{
A histological study of the skin, hair follicles and moult of the hooded seal (Cystophora cristata [Erxleben, 1777])
}

\author{
John K. Ling \\ South Australia, Australia
}

\begin{abstract}
The aims of this study were to (1) provide a general description of the hooded seal's integument; (2) diagnose hair follicle activity stages and develop a chronology for the annual moult within the different sex and age classes; (3) examine the population characteristics of the moult haul-out; and (4) seek possible correlations between these events and the hooded seal's annual cycle. Skin samples were collected from 68 moulting hooded seals out of 868 taken in the Denmark Strait for population studies during June and July 1972. The microstructure of the integument of this species is described. It varies little from what is known from other northern phocids. However, they appear to be one to two "intermediate" guard hair follicles within up to seven underfur follicles; these are smaller than the main guard hair follicle in each hair follicle complex. The hair follicles in the skin of most hooded seals of both sexes and all ages sampled between 21 June and 11 July 1972 were at early to middle stages of activity, suggesting that hair growth starts somewhat earlier than mid-June and ends later than mid-July. It appears that female moult haul-out numbers started to decline about four to five days earlier than the males, but when the haul-out began or ended could not be determined. The brevity, synchronicity and precision of the moult (and breeding season) suggest that its timing is controlled by an environmental factor such as day length at the high northern latitudes inhabited by hooded seals.
\end{abstract}

\section{KEYWORDS}

Integument; microanatomy; hair growth cycle; annual cycle; pinniped; fur

\section{ABBREVIATION}

MTS: Masson's trichrome stain

\section{Introduction}

In 1972 I accompanied a Norwegian Fisheries Directorate expedition to the Denmark Strait in the North Atlantic, the primary purpose of which was to collect biological material from hooded seals (Cystophora cristata [Erxleben, 1777]), as part of ongoing studies of their population biology. This species has been exploited, perhaps for centuries, because of its valuable pelts, which are used for the manufacture of various kinds of leather goods and, in the case of young seals ("bluebacks"), luxury furs. I took the opportunity afforded by the harvest to collect skin samples from hooded seals of both sexes and many ages, in order to study the morphology of the integument, hair follicle activity, and hair growth and moulting in this species at the histological level, which had not been investigated systematically up to that time, especially the pelage cycle in relation to the hooded seal's annual cycle. It is very important to understand the histology of hair growth and moulting cycles in seals and, for that matter, fur-bearing mammals in general in the context of other phases of their annual cycles. This will facilitate exploration of cause and effect relationships, particularly in species being exploited for their pelts.

There have been descriptions of various elements of the integument of several species of seals, but few have touched on the dynamics and timing of hair growth which of course are vital for a harvested species, particularly at the histological level. By far the most outstanding study of seal skin is Bergersen's (1931) detailed description of the skin, hair follicles and moult of the harp seal (Pagophilus groenlandicus), the "whitecoat" pups of which have been harvested for their lustrous furs over many centuries. It remains a benchmark in pinniped literature. Bergersen also alluded briefly to the skin and hair of the hooded seal.

Other studies of skin and hair growth in seals include those of Montagna \& Harrison (1957), who investigated the microstructure and histochemistry of the skin of the harbour or common seal (Phoca vitulina); Scheffer (1962), the pelage of the northern fur seal (Callorhinus ursinus); Ling \& Button (1975), the integument of grey seal pups (Halichoerus grypus); and Ling (1965a, 1968) and Ling \& Thomas (1967), the southern elephant seal (Mirounga leonina), which established some form of time frame for hair follicle development and, hence, activity in the course of this species' annual cycle. Ling (2013) described the cyclic activity of hair follicles in this species, the diagnosis of which enabled the hair growth cycle to be followed over a course of time and some chronology of subcutaneous events to be determined in relation to other 
phases of the elephant seal's annual cycle for the first time in any pinniped.

In their study of the prenatal development of hair follicles and the postnatal moult in southern elephant seal foetuses and pups, Ling \& Thomas (1967) recognized 10 stages in the production of the first fully formed coat (lanugo), which took approximately 14 weeks from follicle primordia to fully grown (resting) hairs. The actual growth of the first hairs began with the hair cone at their Stage 4, after new follicles had developed, from which point hair formation and growth were completed (Stage 10) in about 12 weeks. Chase (1954) stated that each new hair growth cycle replicated the growth of the first hairs, so Stages 4 to 10 were invoked in this study in order to establish the stage of hair follicle activity in each hooded seal skin sample collected in the Denmark Strait during June and July 1972. It is not possible, however, to assign a time frame to the hooded seal's hair growth cycle through lack of a chronology for the various stages, and because of the short collection period over which any stages might occur.

The seven hair growth stages to be invoked may be summarized as follows (with follicles visualized vertically). Stage 4: the new hair starts growth within a cone formed by the internal root sheath - three concentric layers of cells arising from the outer and central parts of the matrix at the base of the follicle (Montagna 1962). Mitotic activity commences within a small mass of cells in the matrix that are the hair precursors, which begin to proliferate up the follicle. The dermal papilla assumes a cylindrical or cigar shape. Stage 5: the tip of the hair cone extends about halfway up the follicle. Stage 6: keratinization of the hair tip occurs within the hair cone just below the level of the sebaceous glands. Stage 7: the hair tip and the internal root sheath margin extend into the hair canal just below its orifice at the skin surface. Stage 8: the new hair emerges from the hair canal to the skin surface. Stage 9: hair growth continues. Stage 10: the hair stops growing and develops a brushlike base before forming a club hair that is enclosed in a cellular capsule of the dedifferentiated part of the nowresting follicle bulb; the dermal papilla cavity or matrix assumes a conical shape and is drawn towards the club hair. The old hairs are then cast off. Pre-moult and postmoult may be designated as Stages 0 and 10+, respectively.

In the absence of any other known moulting area and the paucity of data from tag recoveries, Rasmussen (1960; cited by Reeves \& Ling 1981) believed that almost the entire population of adult hooded seals assembled on the pack ice in the Denmark Strait (the "West Ice") to moult during the northern summer. Their numbers were said to peak between 15 June and 15 July, with some carryover into August.
The objectives of this study were to (1) describe the microstructure of the hooded seal's integument in some detail; (2) diagnose the stage of hair follicle activity and, hence, progress of hair growth and replacement in each seal in space (different body regions) and time; (3) analyse the population characteristics of the moult haul-out with respect to sex and age classes identified in all 868 seals taken by the expedition; and (4) seek cause and effect relationships between the moult and other phases of the hooded seal's annual cycle, and (5) consider factors that might control the timing of these events.

The expedition to and from the Denmark Strait was carried out aboard the MS Flemsøy, a 30-metre sealing vessel out of Ålesund, Norway. Operations centred on the pack ice in the Denmark Strait off Angmagssalik in East Greenland $\left(67^{\circ} \mathrm{N}, 32^{\circ} \mathrm{W}\right)$ between 20 June and 11 July 1972. A total of 868 hooded seals were killed for the main purposes of the expedition, which were to analyse age and reproduction in this species as part of long-term population studies by the (then) Norwegian Fisheries Directorate. Skin samples were collected from 68 seals of both sexes and many ages for the study now being reported.

As it is most unlikely that the killing of such large numbers of hooded seals would be permitted today even the 68 for studies of the integument - it is important to note this was carried out when commercial hunting of this species was allowed, and none of the seal skins was "wasted". The historical perspective of this paper should not be lost sight of.

\section{Materials and methods}

\section{Collection methods}

Seals were randomly shot through the head at close range with a high-powered rifle from the ship as it motored quietly between the ice floes on which they were resting. A long line was run out from the ship's side and attached to one or two dead seals which were then winched onboard. If an animal appeared not to be quite dead, it was killed with a blow to the head with a harpik, piercing the brain.

As part of the population biology studies of the then commercially harvested hooded seal nose-tail lengths, axillary girths, blubber depth and rectal temperatures were measured and sex was recorded for each seal. Reproductive tracts were taken from some of each sex, and a canine tooth extracted from every seal for age determination. This was carried out in the laboratory by sectioning teeth and counting cementum layers (annuli) thus revealed. Ages of only eight (five males and three females) of the 868 seals killed could not be determined. Skin samples were collected from approximately every twelfth hooded seal of the 868 that were killed. 


\section{Skin sampling method}

Skin samples were excised using a 1-cm-diameter trephine, which cut a disc through the epidermis and dermis down as far as the upper level of the hypodermis (blubber or fat layer). As the trephine was withdrawn it pulled the disc of skin away from the hypodermis to which it remained attached by a strand of stretched blubber, which was then cut to free the specimen. Because the seal pelts were to be sold to partly defray the cost of the expedition, most skin samples were excised from the chest region over the sternum to avoid damaging the whole pelt (which was flensed off starting with a cut along the ventral midline). In the case of four seals, skin samples were taken from 11 body sites on one and six on the other three, reducing the commercial value of the pelts. These sites were the neck (dorsal), back (between the clavicles), rump (just anterior to the tail), throat, chest, belly, axilla, fore-flipper (dorsal and ventral) and hind-flipper (dorsal and ventral).

Skin samples were fixed in $10 \%$ phosphate-buffered formalin for a few days and then transferred to a fresh batch of the same solution for storage. Skin samples taken from more than one body region for the purpose of describing the hooded seal's integument in more detail were fixed in Bouin's fluid for a few days and then transferred for storage to $70 \%$ ethanol containing $5 \%$ glycerol to prevent hardening. Bouin's fluid was chosen because of the excellent microanatomical detail produced by this fixative (Carleton \& Drury 1957).

\section{Preparation for microscopy}

The preserved material was not treated for study until 1990 , some 18 years after it was collected. Samples were prepared for wax-embedding, sectioning and staining by trimming off the hairs with fine scissors as close as possible to the skin surface. The discs were then sliced vertically in half between the hair stumps and parallel to the long axes of the hair follicles with a new single-edged safety razor blade, as illustrated by Ling \& Button (1975). Both half discs were treated in an automatic tissue processor and then one was embedded in bee's wax with the cut face pressed gently against the bottom of the embedding tray. This face was used to orientate the tissue block on the microtome to cut vertical sections of hair follicles as accurately as possible at $8 \mu \mathrm{m}$ and $10 \mu \mathrm{m}$ thickness. Some of the other half discs were embedded with the skin surface pressed against the bottom of the embedding tray, so that transverse sections (i.e., parallel to the skin surface) could be cut.

For diagnosing follicle activity only, 10 microscope slides were prepared with three to five or six vertical skin sections mounted on each slide for every seal sampled. Four to six were stained with haemalum, eosin and picric acid after Carter \& Clarke (1957), and four to six were stained with MTS after Gurr (1969). The former stain exposed nuclei and transition within proliferating cells of the follicle bulbs, and its picric acid content clearly identified signs of keratinization in growing hairs. MTS also showed up nuclear activity as well as connective tissue. When skin samples from up to 11 body sites were to be studied for descriptive purposes the same procedure was applied to each sample. Up to 155 slides resulted from cutting transverse sections of skin from each of six seals as far down as the base of the hair follicles. The first five slides were stained with haemalum, eosin and picric acid, the next five with MTS and so on to the last slides.

All slides were examined on a simple Cambridge Instruments Galen III compound microscope (magnification: $10 \times$ to $1000 \times$ ) in the author's home without any other equipment being used. Even with very poor orientation or staining of the skin sections it was possible to find a follicle bulb or part thereof sufficient to diagnose its stage of activity. While carrying out the diagnosis of hair follicle activity and stages of hair growth, the general microstructure of the skin, hair follicles and associated glands was also surveyed briefly, and any particular features noted to aid a subsequent more detailed study of the hooded seal's integument.

To reduce possible bias, if not eliminate it completely, all skin samples were examined at random (i.e., not according to collection date) and observations were recorded under field collection number only (even a lower or higher number gave some idea of when the sample was collected). When all samples had been studied, collection dates and details of age, size and sex were added to the diagnostic record of hair follicle activity. Only this author carried out the microscopic examination of the skin samples; there was no checking by another person.

\section{Results}

\section{Epidermis}

In vertical sections of skin, the epidermis presents a folded profile due to it spilling over to line the hair canals. These are actually elongated, inverted cones, narrow at their proximal end and wider distally at the orifice. The epidermis continues down deeper into the dermis as the external root sheath, forming the wall and matrix of each hair follicle. The epidermis typically consists of a series of cell layers and their derivatives: a single basal layer of more or less cuboidal cells forming the stratum basale (malpighii); two to three layers of ovoid cells constituting the stratum granulosum; one or two layers of more flattened or 
lenticular cells of the stratum spinosum; a layer of hyaline material, the stratum lucidum; and the outer keratinized horny layer, the stratum corneum. The latter consists of as many as 12-20 flattened sheets or lamellae that remain in contact with each other at points along their interface before finally separating and sloughing off altogether; in side-view, it is somewhat like wire chicken mesh.

In the 11 body sites that were examined, the thickness or depth of the epidermis varied from 42 to $135 \mu \mathrm{m}$. There was a slight suggestion that the epidermis on the ventrum and flipper regions may have been marginally thicker than on dorsal surfaces, but this was not tested statistically.

Interspersed with the basal layer in some, but not all, samples were varying densities of dendritic melanocytes, which manufacture pigment granules in the lower levels of the epidermis. The undersurface of this basal layer was not smooth; instead, it presented a somewhat papillated profile in the upper level (the papillary layer) of the dermis. None of the skin samples showed dense pigment in the epidermis at this time when hair follicles were most active. Although not looked for specifically when handling the seals, there was little pigmentation ("bluing") on the skin surface. Whether this pigmentation would dissipate completely at the conclusion of new hair growth and a "prime" condition of the coat reached (indicated by pink skin as observed in many terrestrial fur-bearers) could, of course, not be determined.

\section{Pelage and hair follicles}

Juvenile animals presented a uniformly grey dorsal coat that shifted to creamy grey ventrally. In adults, the grey areas gave way to irregular patches of variable size and shape, larger on males than females, on a grey background, and larger dorsally than ventrally.

The hooded seal's adult-type pelage consists of guard hairs and underfur, whose follicles are associated with sebaceous glands and sweat glands, forming pilosebaceous units or hair follicle complexes. The studied guard hairs were lanceolate in shape flattened and terminating in a sharp point. They were up to $12 \mathrm{~mm}$ long and approximately $0.25-0.5 \mathrm{~mm}$ wide; their detailed structure was not investigated. Their tips tended to curl when the coat was dry.

In vertical sections of skin, the guard hair follicles (sliced longitudinally) could be seen to penetrate the dermis almost to the hypodermis. They made an angle of about $60^{\circ}$ to the skin surface and in their most active state, as seen in almost all of the material collected for this study, reached a length of approximately 3.5-3.8 mm, and their bases lay about 2.8$3.0 \mathrm{~mm}$ vertically below the skin surface. The side of the follicle making the obtuse angle to the skin surface is termed the ental (i.e., "inside") side and the side of the follicle making the complementary acute angle to the skin surface is known as the ectal (i.e., "outside") side. Two to four follicles, smaller than those of the main guard hairs, could be seen to contain what might be termed "intermediate" guard hairs. In sections cut parallel to the skin surface, however, as many as seven small follicles were exposed in cross-section, with six being the common number on various parts of the body, but with only three being associated with each guard hair follicle on the flippers. Only in one sample could underfur be seen entering the hair canal on the ental or caudal side of the guard hair follicle.

Most guard hair and "intermediate" and underfur follicles were in an active (i.e., anagen) stage of growth, with actual hairs ranging from advanced hair cones starting to keratinize at the distal end to growing hair shafts emerging from the hair canal onto the skin surface. These events were associated with the annual pelage change or moult which is described later on in this paper.

The guard hair follicles and their cellular components mirror the typical mammalian pattern to a very close degree. They are enclosed in a connective tissue sheath of the dermis, part of which enters the hair bulb as the dermal papilla, which undergoes changes during the hair growth cycle, as described later. A glassy or vitreous membrane was observed between the external root sheath and the connective tissue sheath in both vertical and transverse sections of follicles. Within the bulb itself the inner margins of the matrix contain varying quantities of dendritic melanocytes, which produce pigment granules that become incorporated into the cortex of the hair shaft. In most of the skin samples examined, mitosis was observed to be taking place in the matrix and cells were becoming more fusiform in shape as they proliferated into the growing hair.

A single layer of cells - Henle's layer - lay adjacent to the inner side of the external root sheath and surrounds a layer of two to three cells - Huxley's layer - further inwards of which is a single layer of internal root sheath cuticle cells. As the hair cone and young hair grow, these cells could be seen to imbricate themselves with cuticle cells of the growing hair. From this a hair surface scale pattern would emerge, but this was not investigated in this study.

The underfur follicles had the same structure as the larger guard hair follicles, with all the respective cellular layers around them. Their bulbs were located at a level about two-thirds along the length of the guard hair follicles. However, the bases of all types of follicles lay at slightly different levels relative to each other. The underfur follicles were also at the same stages of growth as the larger follicles within each hair bundle. They were located on the ental side of 
the guard hair follicles, i.e., within the obtuse angle between the follicle and skin surface.

\section{Skin glands}

Hair follicle complexes have sebaceous glands and sweat glands associated with them, hence, the more common term, pilosebaceous units. Sebaceous glands, gorged with fat cells, occur in upper levels of the skin, either as clusters of acini around the lower part of the hair canal, elongated bodies lying alongside the follicle, or even as apparently isolated fat bodies in the papillary layer or other parts of the dermis, seemingly detached from the hair follicles.

The bunched acini around the hair canal are irregular in shape and the "floating" ones in the upper levels of the dermis are ovoid, cylindrical or irregular in shape. Cylindrical glands measure up to $870 \mu \mathrm{m}$ in length and $80 \mu \mathrm{m}$ in diameter and ovoid glands are up to $575 \mu \mathrm{m}$ in length and $175 \mu \mathrm{m}$ in maximum diameter. Thus, they are relatively small compared with the size of the guard hair follicles with which they may or may not be associated. In this study, sebaceous ducts were clearly observed in vertical skin sections, leaving the acini and longitudinal glands and entering at the bottom of the hair canal. However, no ducts could be seen in any association with the isolated masses of fat cells, so the fate of their secretions could not be determined.

Viewed in both vertical and horizontal sections of skin, it appeared that not every hair follicle complex had an associated sweat gland. Where they did occur, the sweat gland tubules and duct were often located on one side of the follicle or the other. The glands themselves were situated near or even just below the guard hair follicle bulb, in the form of a mass of coiled tubules that straightened out about half-way alongside the follicle, to become the ascending sweat duct. The sweat duct passed on either side of the follicle or between the underfur follicles and the guard hair follicle. At its distal end the sweat duct tapered almost to a point, with no discernible opening, wherever that might have been. Where the sweat ducts terminated in relation to the sebaceous gland openings into the hair canal could not be determined in either vertical or horizontal sections of the skin.

The sweat glands are of the apocrine type, i.e., they form as outgrowths of hair follicles and secrete all or only a portion of their cytoplasmic contents. The tubules and ducts consist of a single layer of cuboidal cells forming the gland and duct walls. The external and internal diameter of the tubules and duct varied from 57 to $83 \mu \mathrm{m}$ (mean of $69 \mu \mathrm{m}$ ) and 29 to $57 \mu \mathrm{m}$ (mean $42 \mu \mathrm{m}$ ), respectively.

Sweat glands appeared subjectively to be more numerous and larger in four samples of skin from the front and hind flippers. This was even more noticeable in skin from the ventral side of the slippers. However, because of the nature and morphology of the sweat glands, being much coiled, it was not possible to carry out any meaningful measurements to verify these observations.

\section{Dermis}

In vertical sections of skin, the papillary layer of the dermis exhibits a rather compact mass of collagenous connective tissue interspersed with peripheral blood vessels. The reticular layer is more open and contains bundles of collagen fibres running parallel to the skin surface, as well as several non-staining bodies of nucleated cells at the lower level of the dermis, just above the hypodermis. In this study, when viewed in sections cut parallel to the skin surface, these white bodies were not visible. Their nature and function were not investigated further. The bundles of collagen fibres form a definite triangular-to-polygonal mesh enclosing the hair follicle complexes. Blood vessels were seen interspersing these bundles, but the histological regime did not permit a detailed investigation of peripheral blood vessels, and arteriovenous anastomoses, as described in Cystophora by Bryden (1978), were not observed by this author. Nerves were not detected either, probably because of the histological techniques used.

\section{Population characteristics of the moult haul-out}

Of the 868 seals collected for the principal purposes of the expedition, there were 493 (57\%) males and 375 (43\%) females. In the case of the 68 randomly selected seals from which skin samples were taken for the purpose of studying the integument and moult of Cystophora, there were 43 (63\%) males and 25 (37\%) females: approximately the same sex ratio as that of the entire sample assemblage. The similarity of the compositions of the two samples suggests that the skin samples are reasonably representative of the moulting hooded seal population.

The daily numbers of seals of each sex taken by the expedition are set out in Table 1. The average daily count for males was 33 and for females it was 25 . The highest counts were 73 for both sexes on 29 June and 69 for males on 4 July. The build-up of numbers of males and females over the study period appears to be roughly similar for both sexes but the decline in female numbers occurs slightly before that of the males. The accumulated percentages of the latter also lagged behind those of females, by about two days, again suggesting that the female haul-out may be slightly in advance of that of the males. Moreover, female numbers appeared to be declining slightly after 4 July, whereas those of the males continued around the male average well after that date.

Mean ages of male and female hooded seals taken on each day of the study are summarized in Table 2. Except 
Table 1. Numbers of male and female hooded seals collected in the Denmark Strait between 20 June and 11 July 1972.

\begin{tabular}{|c|c|c|c|c|c|c|}
\hline \multirow[b]{2}{*}{ Date } & \multicolumn{3}{|c|}{ Males } & \multicolumn{3}{|c|}{ Females } \\
\hline & $\mathrm{N}$ & Percentage of total & Accumulated percentage & $\mathrm{N}$ & Percentage of total & Accumulated percentage \\
\hline $20 / 6$ & 2 & 0.41 & 0.41 & 3 & 0.80 & 0.80 \\
\hline $21 / 6$ & 14 & 2.84 & 3.25 & 22 & 5.87 & 6.67 \\
\hline $22 / 6$ & 33 & 6.69 & 9.94 & 39 & 10.40 & 17.07 \\
\hline $28 / 6$ & 42 & 8.52 & 18.46 & 38 & 10.13 & 27.20 \\
\hline $29 / 6$ & 73 & 14.81 & 33.27 & 73 & 19.47 & 46.67 \\
\hline $1 / 7$ & 9 & 1.83 & 35.10 & 12 & 3.20 & 49.87 \\
\hline $2 / 7$ & 36 & 7.30 & 42.40 & 32 & 8.53 & 58.40 \\
\hline $3 / 7$ & 56 & 11.36 & 53.76 & 35 & 9.33 & 67.73 \\
\hline $4 / 7$ & 69 & 14.00 & 67.76 & 35 & 9.33 & 77.06 \\
\hline $5 / 7$ & 45 & 9.13 & 76.89 & 21 & 5.60 & 82.66 \\
\hline $7 / 7$ & 7 & 1.42 & 78.31 & 6 & 1.60 & 84.26 \\
\hline $8 / 7$ & 29 & 5.88 & 84.19 & 24 & 6.40 & 90.66 \\
\hline $9 / 7$ & 47 & 9.53 & 93.72 & 19 & 5.07 & 95.73 \\
\hline $10 / 7$ & 9 & 1.83 & 95.55 & 3 & 0.80 & 96.53 \\
\hline $11 / 7$ & 22 & 4.46 & 100.01 & 13 & 3.47 & 100.00 \\
\hline Total & 493 & & & 375 & & \\
\hline
\end{tabular}

Table 2. Daily mean ages and age ranges of moulting male and female hooded seals collected in the Denmark Strait, June - July 1972.

\begin{tabular}{|c|c|c|c|c|c|c|}
\hline \multirow[b]{2}{*}{ Date } & \multicolumn{3}{|c|}{ Males } & \multicolumn{3}{|c|}{ Females } \\
\hline & $\mathrm{N}$ & $\begin{array}{l}\text { Mean } \\
\text { age } \\
\text { (years) }\end{array}$ & $\begin{array}{c}\text { Age } \\
\text { range } \\
\text { (years) }\end{array}$ & $\mathrm{N}$ & $\begin{array}{l}\text { Mean } \\
\text { age } \\
\text { (years) }\end{array}$ & $\begin{array}{c}\text { Age } \\
\text { range } \\
\text { (years) }\end{array}$ \\
\hline $20 / 6^{a}$ & 2 & $1.5 \pm 0.5$ & $1-2$ & 3 & $2.0 \pm 0.5$ & $1-3$ \\
\hline $21 / 6^{b}$ & 14 & $7.0 \pm 1.1$ & $1-17$ & 22 & $4.9 \pm 2.6$ & $1-11$ \\
\hline $22 / 6^{b}$ & 32 & $5.2 \pm 1.5$ & $1-15$ & 39 & $4.7 \pm 3.8$ & $1-20$ \\
\hline $28 / 6^{b}$ & 42 & $5.2 \pm 3.7$ & $1-14$ & 38 & $4.2 \pm 3.4$ & $1-17$ \\
\hline $29 / 6^{b}$ & 73 & $4.8 \pm 3.7$ & $1-17$ & 71 & $6.1 \pm 5.9$ & $1-31$ \\
\hline $1 / 7^{a}$ & 9 & $8.3 \pm 5.2$ & $1-17$ & 12 & $7.0 \pm 7.5$ & $2-30$ \\
\hline $2 / 7^{b}$ & 36 & $7.1 \pm 4.4$ & $1-16$ & 32 & $4.6 \pm 3.8$ & $1-14$ \\
\hline $3 / 7^{b}$ & 54 & $7.7 \pm 4.3$ & $1-19$ & 34 & $5.9 \pm 0.8$ & $1-22$ \\
\hline $4 / 7^{b}$ & 67 & $7.0 \pm 3.7$ & $1-16$ & 35 & $5.5 \pm 3.9$ & $1-13$ \\
\hline $5 / 7^{b}$ & 45 & $8.2 \pm 4.5$ & $1-18$ & 21 & $6.7 \pm 5.3$ & $1-20$ \\
\hline $7 / 7^{\mathrm{a}}$ & 7 & $5.6 \pm 5.8$ & $2-19$ & 6 & $3.8 \pm 2.6$ & $1-8$ \\
\hline $8 / 7^{a}$ & 28 & $6.7 \pm 3.8$ & $1-16$ & 24 & $5.1 \pm 1.5$ & $1-14$ \\
\hline $9 / 7^{b}$ & 46 & $8.0 \pm 5.2$ & $1-22$ & 19 & $4.8 \pm 3.5$ & $1-16$ \\
\hline $10 / 7^{a}$ & 9 & $5.6 \pm 2.9$ & $3-11$ & 3 & $9.7 \pm 6.3$ & $1-15$ \\
\hline $11 / 7^{b}$ & 22 & $6.2 \pm 3.0$ & $1-12$ & 13 & $3.9 \pm 2.3$ & $1-9$ \\
\hline
\end{tabular}

for the first day, 20 June, all samples contained a wide range of ages, albeit with some missing, in particular, much older animals. The mean age of males ranged from four to eight years and for females it was four to almost 10 years. A 22-year-old male was collected on 9 July and a 31-year-old female was taken on 29 June. There is, however, no clear pattern of average age of either sex increasing over the course of the study period as the moult haul-out progressed to indicate that the moult schedule was age-related. One-year-old seals of both sexes occurred in almost every sampling day. It would appear that all ages of both sexes moult almost simultaneously.

\section{Hair follicle activity, hair growth and moulting}

The stages of hair follicle activity were studied in skin samples collected from 43 male and 25 female hooded seals and the findings are summarized in Table 3. As some stages could not always be sharply differentiated from the one before or the one after, observations were sometimes recorded as ranges, e.g.,
Table 3. Daily pelage follicle activity stages in male and female hooded seals collected in the Denmark Strait, June July 1972.

\begin{tabular}{|c|c|c|c|c|}
\hline \multirow[b]{2}{*}{ Date } & \multicolumn{2}{|c|}{ Males $(\mathrm{N}=45)$} & \multicolumn{2}{|c|}{ Females $(\mathrm{N}=23)$} \\
\hline & Activity stages & $\bar{N}$ & Activity stages & $\mathrm{N}$ \\
\hline $21 / 6$ & $4-6$ & 8 & - & - \\
\hline $22 / 6$ & 5 & 1 & $4-5,7-8,10+{ }^{a}$ & 6 \\
\hline $28 / 6$ & $5-8$ & 4 & $6-8$ & 2 \\
\hline $29 / 6$ & $5-7$ & 3 & $5-6,8$ & 5 \\
\hline $1 / 7$ & $6-8$ & 2 & - & - \\
\hline $2 / 7$ & $5-10+{ }^{a}$ & 6 & $5-6$ & 2 \\
\hline $3 / 7$ & $5-8$ & 5 & $8-10+$ & 2 \\
\hline $4 / 7$ & $5-7$ & 5 & $6,9-10^{a}$ & 2 \\
\hline $5 / 7$ & $5-7$ & 3 & $6-7$ & 2 \\
\hline $7 / 7$ & 7 & 1 & $5-6$ & 2 \\
\hline $8 / 7$ & 7 & 2 & $4-5$ & 2 \\
\hline $9 / 7$ & 10 & 1 & - & - \\
\hline $10 / 7$ & 6 & 1 & - & - \\
\hline $11 / 7$ & $5-6$ & 1 & - & - \\
\hline
\end{tabular}

${ }^{a}$ Not all intermediate stages.

5-6, etc. Moreover, because of the small number of samples collected on some days, all stages from 4 to $10+$ were not observed on any particular day.

Over the three-week sampling period only one male and two female hooded seals had hair follicles at activity Stage 4; the great majority were at Stages 5 to 7: 34 of 43 males (79\%) and 15 of 25 females (60\%). The follicles of eight males (19\%) and eight females (32\%) were at or beyond Stage 8 . There was no obvious progression from early to later stages between the first and last days of sampling. A male and a female appeared to have completed follicle activity (Stage 10) and two males and two females were diagnosed as post-moult (Stage 10+) from the state of their hair follicles. However, the occurrence of Stages 0 and $10+$ was quite random with respect to date and were not necessarily observed only during the earlier and later stages of the expedition, respectively. Neither was there a clear pattern to suggest any relationship between age and the timing of follicle activity and the moult, i.e., hair follicle activity stages were spread randomly among the various ages of seals of either sex. Furthermore, in four instances when several (six to 11) body sites were sampled, there was great similarity in the 
Table 4. Hair follicle activity stages at six to 11 body sites on four adult hooded seals collected in the Denmark Strait, June - July 1972.

\begin{tabular}{|c|c|c|c|c|}
\hline \multirow[b]{4}{*}{ Body site } & \multicolumn{4}{|c|}{ Field number } \\
\hline & \multicolumn{4}{|c|}{ Sex/age (years) } \\
\hline & $72 / 7$ & $72 / 161$ & $72 / 532$ & $72 / 697$ \\
\hline & Male/2 & Female/17 & Male/1 & Female/1 \\
\hline 1 Neck & - & 8 & $7-8$ & $6-7$ \\
\hline 2 Back & 4 & $5-7(?)$ & $6-7,7-8^{c}$ & 5 \\
\hline 3 Rump & $4-5,6$ & $5-7(?)$ & 7 & - \\
\hline 4 Throat & - & 8 & 8 & 7 \\
\hline 5 Chest & $4-5$ & $7-8$ & 8 & 5 \\
\hline 6 Belly & 5 & $8-9$ & 7 & $5-6$ \\
\hline 7 Axilla & - & 8 & $5-6$ & 5 \\
\hline 8 Fore flipper $\left(d^{a}\right)$ & 4 & $6-7$ & $6-7$ & $4-5$ \\
\hline 9 Fore flipper $\left(v^{b}\right)$ & 5 & 6 & 7 & 6 \\
\hline 10 Hind flipper (d) & - & $6-7$ & $7-8$ & $5-6$ \\
\hline 11 Hind flipper (v) & - & $8-9$ & 8 & $5-6$ \\
\hline
\end{tabular}

${ }^{\text {a }}$ Dorsal. ${ }^{\mathrm{b}}$ Ventral. ${ }^{\mathrm{c}}$ Two samples.

stages of hair follicle activity in all body and flipper regions of each seal (Table 4). In other words, hair growth and replacement appeared to proceed at a uniform rate over the entire body and flippers of individual seals. It is also noticeable that hair follicle activity in the earliest and latest samples - as denoted by daily collection numbers - was, generally speaking, at earlier stages than in those taken in the middle of the sampling period; one a one-year-old male and the other a 17-year-old female. Judging from the amount of shed hair covering the ice floes, and giving them a very "dirty" appearance, the moult proceeded quite rapidly among the seals present. While underfur follicles were also active - at about Stage 6 - there was no sign as to if or when some or all of the underfur might be replaced; or where or when it might emerge in relation to the guard hairs.

\section{Discussion}

\section{General comments on the study}

At the outset it should be noted that the material for this study was collected more than 45 years ago, when hooded seals were being hunted commercially. Today, the killing of such large numbers of seals (or most other animals for that matter) for scientific purposes probably would not be allowed. In any case, the "West Ice" hooded seal population is now totally protected, having declined by $85 \%$ (Øigård et al. 2014). However, the species is still hunted by quota in Canada (Kovacs 2016).

As the main purpose of the expedition was to collect material from moulting hooded seals in the Denmark Strait for studies of their population biology, it is important that the 868 (57\% male, $43 \%$ female) animals taken represented the natural population as closely as possible. I believe that the material is a fair sample of the population because the seals were randomly shot as and when they were within range on the pack ice. The 68 ( $66 \%$ male, $34 \%$ female) seals sampled for the purposes of this paper also approximated the entire sample and are therefore believed to be reasonably representative of the hooded seal population insofar as numbers and sex ratios of moulting seals are concerned. However, the sample size is too small for conclusions to be drawn about relations between moulting time and age or sex. Moreover, because all of the material obtained for the purposes of this study was collected over a period of only three weeks (20 June to 11 July 1972), any variations in a number of features and dynamics that might occur over a longer time frame would not be observed. For this reason no statistical analyses were carried out. There also were interruptions to the collecting programme due to bad weather and ice conditions (the vessel was held fast in the pack ice from 23 to 27 June, and seals were not accessible). Also, because such a limited staining regime was employed in the histological study, which primarily was directed at diagnosing hair growth stages during the moult, microscopic and histochemical insights into the hooded seals integument are not nearly as detailed as they could have been under better conditions. Despite all of these factors, it has been possible to obtain a very good understanding of the microstructure of the hooded seal's integument, its derivatives and events taking place therein leading up to the moult.

\section{Integument}

The hooded seal's integument is similar to that of other phocids except, perhaps most strikingly, that of the monachine elephant (Mirounga spp.) and monk seals (Monachus spp.), which shed their fur along with large ragged patches of cornified epidermis. As in all seal species whose integuments have been investigated, the absence of arrectores pilorum (erector) muscles attached to the hair follicles allows the fur to lie flat over the body when wet and the seals are swimming. It is interesting, incidentally, to note that taxonomists formerly placed hooded and elephant seals together in their own subfamily Cystophorinae, based on the possession by adult males of a large inflatable nasal bladder by the former and an inflatable proboscis by elephant seals. King (1966) used skull features and other criteria - but not the integument - to include Cystophora in the northern phocid subfamily Phocinae and group monk and elephant seals in the subfamily Monachinae, which undergo similar catastrophic moults.

Cystophora's pelage grows out of pilosebaceous units or bundles of guard hairs and underfur. The structure of individual hairs was not investigated in this study, but Bergersen (1931) described them in detail. He stated that guard hairs and underfur measured up to $13 \mathrm{~mm}$ and $10 \mathrm{~mm}$ in length, 
respectively. The former are almost flat in cross-section beyond their roots, while the latter are more rounded or oval in cross-section. Neither guard hairs nor underfur have a medulla but pigment granules are present along much of the central cortex. Bergersen (figure 15, 1931) illustrated the cuticular scale patterns of hooded seal guard hairs.

In some, but not all, follicle complexes of this seal there appear to be one or two follicles of intermediate size between guard hair and underfur follicles. This study found that Cystophora has a guard hair and up to six or seven underfur (including "intermediate") hair follicles per bundle. Of the other northern phocids whose integuments have been described, the common or harbour seal (Phoca vituline), has one, rarely two, guard hairs and four to five underfur follicles (Mohr 1950). Mohr's second guard hair, when present, may be analogous to the "intermediate" hairs found in Cystophora. Whether these function as guard hairs or underfur could not be determined.

In his extensive study of hair patterns in seals, Scheffer (1964) made impressions of fresh, preserved or tanned sheared skin surfaces of 20 pinniped genera. Among samples of northern phocids he showed that Pagophilus, Phoca (vitulina), Histriophoca and Halichoerus have 3-5, 3-6, 2-6 and 4-7 underhairs, respectively. Scheffer noted that there are 23 guard hairs per $10 \mathrm{~mm}^{2}$ in Cystophora and each hair bundle contained 4-6 underhairs with a mode of five. His photograph of the hooded seal's sheared skin surface (figure 3,1964) clearly shows a large guard hair stump and a smaller ("intermediate") underhair stump and up to four fine-hair stumps. Observations in this study agree with this finding. Scheffer's plate IC (1964) shows that Pagophilus has a guard hair, an "intermediate" hair and underhairs, but he states in table 1 (p. 293) that there are 3-5 of the latter in each hair bundle. He also published sketches of birthcoat and the first adult-type pelage hairs in the northern fur seal (Callorhinus ursinus) showing large and smaller guard hairs along with three "intermediate" hairs.

Bergersen's (1931) figure 18 depicts transverse sections of hair follicle complexes in Cystophora cristata, which include club hairs, replacement growing guard hairs, underfur follicles, sweat ducts and sebaceous glands. In cross-section, the follicles appear to differ in size, but this could be due to each follicle bulb being transected at different levels across different diameters. There is no sign of any "intermediate" hair follicles in cross-section, but they showed up quite clearly in vertical skin sections in this study and were larger than underfur follicles but smaller than guard hair follicles.

The skin of Antarctic Ross seals (Ommatophoca rossii) has only one to two underfur follicles associated with each guard hair follicle, and an average of 3.6 guard hairs per $\mathrm{mm}^{2}$. The underfur is denser on the dorsal surface of the body than ventrally, and the hair generally is shorter and sparser on the flippers, and even more so in the interdigital areas of the hind flippers (Polkey \& Bonner 1966). The other Antarctic phocids - leopard seal (Hydrurga leptonyx), crabeater seal (Lobodon carcinophagus) and Weddell seal (Leptonychotes weddellii) - have one, 1-4 and 2-5 underfur follicles in each hair bundle, respectively (Scheffer 1964). These seal species clearly depend on a thick layer of blubber for insulation.

The southern elephant seal (Mirounga leonina) does not possess any underfur (Ling 1965a, 1968) nor does its northern counterpart, $M$. angustirostris; the related monk seals (Monachus spp.) also have no underfur (Scheffer 1964).

While Cystophora does have an insulative blubber layer up to $5 \mathrm{~cm}$ deep (Ling, unpubl. data), the underfur and the "intermediate" hairs assist in thermoregulation by trapping air below the overlapping flattened guard hairs. Perhaps, therefore, these two types of smaller (than the guard hair) types should be considered as one regarding this function, with the guard hairs providing the protective and waterproofing cover. However, the guard hairs and "intermediate" hairs are in no way analogous to the primary and secondary wool fibres identified by Hardy \& Lyne (1956) and Lyne (1957) that are grown in branching follicles of sheep.

Erdsack et al. (2015) reported that hair bundles on the back and top of the head of the harbour seal were of a typical mammalian pattern, consisting of a guard hair and underfur composed of 2-4 underhairs. On the mystacial and supraorbital vibrissa pads, however, hair bundles showed a completely different make-up: a guard hair, two to three thinner, but still flattened, "intermediate" guard hairs and either no underhairs or, in the case of the supraorbital vibrissa pads, just one underhair. These authors found hair bundle density per unit area to be similar $(8.2 \pm 1.2$ to $8.7 \pm 1.4)$ on the body and mystacial and supraorbital vibrissa pads, but significantly higher $(10.5 \pm 1.1)$ around the rhinal vibrissae. Total hair density was also significantly higher on the rhinal vibrissa pads than on the other vibrissal areas, which themselves had higher hair densities than on the body. They concluded that while the vibrissa follicle blood sinuses served to maintain warmth around the sensory hairs, the fur composition described may also provide thermal insulation of the vibrissae as well as drag reduction. This study did not investigate hair bundle composition around the vibrissae. Bonner (1981) described pelage on the mane region of adult male Antarctic fur seal (Arctocephalus gazella), as having coarse outer, and finer inner layer of guard hairs overlaying a dense underfur. It therefore appears that 
"intermediate" hairs are not uncommon in either the Phocidae or the Otariidae.

Kvadsheim \& Aarseth (2002) investigated the insulative role of fur in newborn and adult harp and hooded seals. They found that in air, the fur of harp seal pups contributed $90 \%$ of the combined thermal resistance of blubber, skin and fur, whereas the fur contributed $73 \%$ in newborn hooded seals. In addition, the fur contributed $29 \%$ in adult harp seals and $34 \%$ in adult hooded seals. When submerged, the thermal resistance of the fur was reduced by $84 \%$ to $92 \%$ and contributed $65 \%$ of the total insulation in newborn harp seals and $26 \%$ in newborn hooded seals. The fur contributed only $3 \%$ to insulation in wet adult harp seals and $5 \%$ in wet adult hooded seals. Harp seals are born with their first coat or lanugo, whereas hooded seal pups have already replaced their lanugo with the first adult-type pelage before birth. The latter has been shown in this work to consist of guard hairs and from four to seven underfur follicles. The harp seal's adult pelage also contains up to four (or more) underfur follicles (Bergersen 1931). This may account for the slightly lower contribution by the fur of harp seals to insulation than that of hooded seals when dry or wet in both species; they occupy roughly the same Arctic regions of the North Atlantic (Reeves \& Ling 1981; Ronald \& Healey 1981).

It is possible that the epidermis also plays a small part in thermoregulation by virtue of the stratum corneum lamellae adhering to each other at points of contact between the successive layers. This creates tiny air-filled chambers, which could also assist in thermoregulation in the cold Arctic environment.

Some vertical sections of skin revealed the underside of the epidermis - i.e., below the basal layer - to be somewhat folded and papillated at its junction with the papillary layer of the dermis. This could confer a degree of flexibility to the epidermis, allowing it to bend and stretch under the influence of external water pressure and help to achieve a more streamline, hydrodynamic body shape and reduce turbulence. This papillation was more evident in some seals than others.

The flattened, overlapping lanceolate guard hairs are possibly more important than a flexible epidermis in the role of streamlining by presenting a tough smooth surface to the water flowing over the animal, creating laminar flow and so reducing turbulence, as well as trapping air in the underfur beneath them. The ventral, backwardly directed, guard hairs also have a function out of water: they come into play on slippery surfaces such as snow and ice by providing grip and thereby aiding terrestrial locomotion. Northern people are known to make shoes out of seal skin, the guard hairs of which aid with traction on snow. As well as aiding locomotion (in water and on land or ice), the guard hairs present a smooth tough outer protective covering for the seals.

Probably because of the rather crude histological techniques employed in the study (which was mainly diagnostic in purpose), arteriovenous anastomoses were not observed by the author. Bryden (1978), however, made a careful comparative study of these structures in hooded seals and harp seals using special histological methods. He also investigated arteriovenous anastomoses in Weddell seals and southern elephant seals (Molyneux \& Bryden 1978). In all four of these seals the arteriovenous anastomoses were similarly small simple structures, occurring in the superficial regions of the skin of the entire body and extremities of many, if not most, phocid seal species and have a significant role in temperature regulation (Bryden 1978).

There is some evidence that the ventral side of the hooded seal's flippers have larger and more numerous sweat glands than other parts of the body. Given the hooded seal's Arctic habitat, it is not known whether or to what extent they may need to keep cool, but the presence of more sweat glands on the underside of flippers than elsewhere suggests that their role may be to dissipate heat, perhaps on sunny days. These sweat glands are not nearly as large as those reported for fur seals and sea lions (Sokolov 1958; Ling 1965b). Bearing in mind that the hooded seal material was collected over only a three-week period of the northern summer, when the hair follicles of almost all animals were active, and at their maximum length and depth, the sweat gland tubules would most likely lie well below the level of the follicle base at other times of the year when the follicles are quiescent and shrunken.

While sweat glands and their ducts were clearly visible in many hooded seal skin samples, their actual points of discharge could not be found in any of the material examined. The straightened sweat ducts appeared to "ascend" either between the underfur and guard hair follicles on one side or the other of the follicle complex when viewed in transverse sections. The distal end of the sweat ducts tapered, but their entry into the hair canal or elsewhere through the dermis or epidermis was never seen.

Many of the small sebaceous glands clustered around the base of the hair canal clearly exhibited ducts leading from them into the bottom of the hair canal. However, in the case of the small, isolated sebaceous glands in the upper levels of the dermis, neither ducts nor orifices could be detected, so where they discharged is still not known. It is possible these glands may only appear to be separated from the guard hair follicles because of poor orientation of the vertical skin sections. Bergersen's diagram (figure 57, 1931) depicts six stages of follicle activity during a hair growth cycle in the harp 
seal, one of which (e) shows a sweat duct ascending between a sebaceous gland and the follicle wall. It suggests that the sweat gland may open into the hair canal above the orifice of the sebaceous gland. Another diagram (figure 70, Bergersen 1931) clearly shows the sweat gland opening into the hair canal beyond the opening of the sebaceous gland. This suggests that Bergersen found or believed that the sweat duct opens into the hair canal above the sebaceous gland and this may also be the case in Cystophora, unless it simply dissipates itself in the upper levels of the dermis.

Montagna \& Harrison (1957) stated that the apocrine sweat glands of the common or harbour seal open into the hair canal just below the orifice of the sebaceous glands. The sweat ducts in grey seal pups (Halichoerus grypus) also open slightly below the sebaceous gland into the hair canal (Ling \& Button 1975).

Sokolov (1958) noted that sweat glands are more highly developed in otariids than phocids. $\mathrm{He}$ believed that the flippers play a much more important role in heat dissipation in the former than the latter group of pinnipeds. This could involve sweat glands or the vascular system. He stated, however, that sweat glands in fur seals may be greatly reduced in size and number, or even atrophy, during winter.

In southern elephant seal, the only southern phocid whose integument has been studied in detail, the sebaceous glands open into the hair canal above the sweat gland openings, suggesting that sebum may play a more important role in lubricating or waterproofing the stand-alone guard hairs than sweat in thermoregulation (Ling 1968). It is very interesting to note that Hawaiian monk seals (Monachus schauinslandi) and their monachine relative, the southern elephant seal, both have sebaceous glands opening into the hair canal above the sweat-gland orifice. Neither seal has any underfur. The sebaceous glands are relatively small in Monachus (Whittow et al. 1975), but they are relatively large in Mirounga, where they secrete copious amounts of sebum (Ling 1965b).

The southern elephant seal's sebaceous glands are large in comparison to those of Cystophora. Sebum was believed to play a role in lubricating and possibly waterproofing the hair canal in Mirounga leonina (Ling 1968), but this could be only a very minor function in Cystophora, which, admittedly, is a much smaller animal with a completely different integument and type of moult. In fur seals, sweat glands tend to be large and sebaceous glands relatively small. This trend appears to be related to the thermoregulatory needs inherent in the possession of dense underfur that are met by the secretion of copious amounts of sweat. The sweat ducts also open above the sebaceous ducts into the hair canal of fur seals (Ling 1965b). The Arctic-dwelling hooded seal may have less need for heat dissipation than seals living in lower latitudes.

Histochemical studies by Meyer et al. (2000) have demonstrated the presence of saccharide residues in the sebaceous glands of the common seal. These sugars may act as an antimicrobial protective mechanism by inhibiting the attachment of different pathogens to the epidermis. Other roles of the skin glands of seals also have been proposed. For example, Hardy et al. (1991) suggested that facial skin glands of ringed (Phoca hispida) and grey seals may function as odoriferous organs which might be involved in recognition and other behaviours. This could be in conjunction with the highly tactile vibrissae in this context.

\section{The moult haul-out}

Hooded seals of both sexes, ranging in age from one to 31 years, were randomly sampled over the expedition's three-week stay at the Denmark Strait moulting patch. It has been assumed for the purposes of this study that the daily numbers of seals taken were a reasonable representation of the actual numbers present.

Daily numbers of males and females expressed as percentages of the respective totals (Table 1) suggest that similar increases in numbers of both sexes occurred shortly before the start of the sampling period, with the females possibly arriving a little earlier and beginning to decline in number by early July. The numbers of males appeared to be holding up a little longer and starting to decline later that month, possibly not until after the expedition had left the area. Clearly, Rasmussen's (1960) belief that the principal period of moult is from mid-June to mid-July is borne out by figures in this study. However, the total duration of the moult haul-out might conceivably begin around late May to early June and not end until late July or, as Rasmussen suggests, August. Only a more prolonged study period may resolve this question.

Many ages of both sexes of hooded seals were sampled throughout the three-week collecting period (Table 2), suggesting that this situation would prevail during the entire moult haul-out. The fact, also, that samples included one-year-old animals of both sexes on almost all days of the study period indicates that individual hooded seals may follow their own hair growth and replacement cycle, which can occur at any time in animals of any age during the mount haul-out. Therefore, age or sex does not appear strongly to influence the timing of the moult, although there was a slight trend towards older males moulting a little later in the season, as suggested above. Again, the brevity of the sampling 
period may have obscured any real trend that might be revealed in a longer sampling period, depending, of course, on the availability of seals for skin sampling.

\section{Histology of the annual moult}

There have been few studies at the histological level of the dynamics and chronologies of pelage follicle development, hair growth and replacement in seals and their relationship to the annual cycle. Detailed knowledge about the timing of these events in the hooded seal's hair growth cycle may enable the adaptive value of its life history strategies to be assessed.

Hair follicles actually are formed by indentations of the epidermis which invade the dermis during foetal development (see Ling \& Thomas 1967). A papilla of dermal cells enters the base of the follicle anlage, causing it to invaginate so that the epidermal cells form the matrix or bulb of the follicle from which a hair cone and, eventually, a hair develop. Following the development of the follicles and growth of the first hairs, subsequent hair growth cycles proceed at various intervals according to the species concerned, beginning at that point observed in follicle development when the bulb starts producing the first hair or hair cone (Stage 4), according to Ling \& Thomas (1967).

During the three-week skin sampling period, the great majority of hooded seals of both sexes and all ages were in the middle stages (5 to 7 ) of hair follicle activity according to the criteria established by Ling \& Thomas (1967) for southern elephant seals and refined by Ling (2013). Only two of 68 seals appeared to have either not started or completed hair growth, and only eight of each sex were at late or completed stages (8 to 10). This suggests that the process of hair growth and shedding began earlier than the first day of skin sampling, 21 June, and would not end until some time after the last day, 11 July, of the expedition. It again suggests that there is very little variation in the timing of the hooded seal's moult with respect to either sex or age: it appears to be a precisely timed and concentrated event in this species' life history.

The complete hair growth cycle of Mirounga leonina was determined to be approximately 12 weeks (Ling \& Thomas 1967; Ling 2013). It took approximately four weeks for hair follicles to progress from the beginning of the hair growth cycle (Stage 4) to mid- to late anagen (Stages 7 to 8 ). Hypothetically, if this schedule were applied to Cystophora, hair follicle activity would begin around 24 May, meaning that at the histological level hair replacement would also take about 12 weeks in the hooded seal, ending in late August. Bergersen (1931) found that in an approximately one-year-old hooded seal, hair replacement had progressed very far by 18 August. Montagna \& Harrison (1957) examined hair follicles in Phoca vitulina and found they were at advanced anagen or catagen stage by late August, suggesting a summer moult - albeit slightly later than that which occurs in Cystophora.

All stages of hair follicle activity were observed through the short sampling period of the study reported here and, with the passage of time, more advanced stages were observed; however, every seal seemed to be following its own individual cycle. It was not obvious that age and the timing of hair follicle activity and moult were related. Furthermore, all follicles within a complex were at the same stages of activity, as was also observed in Phoca vitulina by Montagna \& Harrison (1957). Even late-stage follicles were observed throughout the sampling period, regardless of the seals' ages. However, females of all ages did appear to demonstrate slightly more advanced stages of hair follicle activity than males at the same point of the sampling period, indicating that they may commence activity in their hair follicles and complete the moult a little earlier than males.

There did not seem to be any differences in the stages of hair follicle activity at different body and flipper sites; in other words, hair growth and shedding (diagnosed histologically) appear to be synchronous over all parts of each animal, suggesting a mass exodus of hair (witness the very "dirty" ice floes). However, no studies of the external moult and its possible topographical sequence, if any, which might support or, be supported by, the histological evidence, appear to have been reported in the literature. If hair growth and replacement were to occur at the same time across all body areas, a shorter moult cycle might ensue, with consequent physiological advantages to each animal.

\section{Timing of the moult}

Hooded seals have the shortest lactation period of any pinniped - any mammal for that matter (Kovacs 2009) - of only four days (Bowen et al. 1985). This occurs during a breeding season of only about a month from about 10 March to 10 April (Rasmussen 1960; Øritsland 1964), and some three months before the moult haul-out. Energetics may be a crucial factor in the breeding and moult haulouts of this and other species. However, the brevity of the hooded seal's breeding and moulting seasons, their occurrence at certain precise times of the year, and the fact that all ages of both sexes moult almost simultaneously suggest that they may be synchronized directly or indirectly by some environmental cue. At the Arctic latitudes inhabited by hooded seals, day length changes quite rapidly throughout 
the year and would therefore offer a precise timing mechanism within the annual cycle for hair growth to be mediated through the reproductive cycle.

The southern elephant seal's moulting season lasts from November to April or even late May, with different age and sex categories having their own timetable and hair growth taking 12 weeks to complete (Carrick et al. 1962; Ling 2013). In a small sample of adult females, however, $70 \%$ had commenced their hair replacement cycle within a fourweek period between 4 January and 2 February. Moreover, the moult haul-out in this category - also four weeks - is the shortest of any age/sex class (Ling \& Bryden 1981), so there is some precision in the timing of these events. The elephant seal's dramatic moult, in which large patches of dried epidermis peel off with the old hairs attached, may be metabolically more demanding than the simple replacement of pelage hairs such as occurs in Cystophora. The latter also has to contend with the much more rigorous environment in the Arctic. The hooded seal's shorter and more concentrated moulting season may well be an adaptation to this regime.

There may be many other factors that influence the timing of the moult, such as weather or ice conditions. This certainly appears to be the case for many northern fur-bearing mammals. While photoperiod seems to be the most usual proximate factor, altitude and temperature are also known to stimulate moulting in certain land mammals (Ling 1970). It is also known that the responses of different species vary in regard to both hair growth and replacement and reproductive cycles (Ling 2013). As far as pinnipeds are concerned, the reproductive cycle, in particular the birth (and, hence, the conception) date, of the northern fur seal (Callorhinus ursinus) appears to be stimulated by day length of 12.5 hours, at whatever latitude it occurs (Temte 1985). After the precisely timed breeding season, the decline in circulating male and female reproductive hormones, androgen and oestrogen, which are known to inhibit hair growth (Mohn 1958), could be an indirect stimulus for the commencement of moulting in hooded seals.

\section{Conclusions}

This study provides more precise histological insights into the hair growth and replacement cycle of hooded seals than hitherto elucidated by macroscopic field observations. The hooded seal's integument is not remarkably different from what previously has been described for a small number of northern phocids. Its pelage consists of a single lanceolate guard hair, (sometimes) one or two "intermediate" guard hairs and four to six or even seven underhairs (fur), which may include the "intermediates". The skin of the foreand hind-flippers contains a maximum of only three underhairs. The ventral sides of the flippers have slightly larger and more sweat glands, associated with almost every hair follicle complex, than their dorsal surfaces and other parts of the body, where it appears that not every hair follicle complex has an associated sweat gland. Sebaceous glands discharge their product, sebum, via a duct into the lower part of the hair canal, but the outlets for the sweat glands were not discovered in this study; they appeared to discharge into the hair canal above the sebaceous glands or even into the upper dermis well beyond the bottom of the hair canal and dissipating into the dermal tissue, the precise mechanism of which could not be determined, while others apparently enter the hair canal below the sebaceous gland orifice. The hair follicles in the skin of most hooded seals of both sexes and all ages sampled between 21 June and 11 July 1972 were at early to middle stages of activity, which is believed to begin and end a few weeks outside these dates.

Within the limits of the short study period, it appears that the female moult haul-out numbers start to decline about four to five days earlier than the males, but when the haul-out actually begins or ends could not be determined. The duration of the whole process of hair growth and replacement in individual animals could not be established, but it probably begins some time before the start of the moult haul-out and ends after the seals return to sea: probably no earlier than late May and no later than early August, respectively, i.e., approximately 10 to 12 weeks. Thus, the moult is compressed into a very restricted time frame, with great synchronicity between both sexes and all ages, probably as an adaptation to the short season and rigorous Arctic environment. It seems most likely that photoperiod controls the timing of the hooded seal's pelage cycle and moult, either directly by stimulating hair follicle activity through neuroendocrine pathways, or indirectly by a decline in circulating hair growth-inhibiting reproductive hormones after the breeding season ends.

\section{Acknowledgements}

I am very grateful to the late Dr Torger Øritsland of the Norwegian Fisheries Directorate for inviting me to join and participate in the expedition's programme. For the many courtesies, friendship and assistance extended to me by the expeditioners, ship's captain and crew, I am truly grateful. Ms Tina Lavranos prepared the skin samples for microscopic study in the Medical School of the University of Adelaide; I am grateful for the use of the school's equipment and facilities. I thank Drs Kit M. Kovacs and Tore Haug for encouraging me to publish this old work, and I thank Dr Kovacs for transforming my original text into electronic journal format. Two anonymous reviewers made many helpful comments on the manuscript. 


\section{Disclosure statement}

No potential conflict of interest was reported by the author.

\section{References}

Bergersen B. 1931. Beiträge zur Kenntnis der Haut einiger Pinnipedien. Unter besonderer Berücksichtigung der Haut der Phoca groenlandica. (Adding knowledge to the skin of some pinnipeds, with special consideration of the skin of Phoca groenlandica.) Oslo: Norwegian Academy of Science.

Bonner W.N. 1981. Southern fur seals, Arctocephalus (Geoffroy Saint-Hilaire and Cuvier, 1826). In S.H. Ridgway \& R.J. Harrison (eds.): Handbook of marine mammals. Vol. 1. The walrus, sea lions, fur seals and sea otter. Pp. 161-208. London: Academic Press.

Bowen W.D., Oftedal O.T. \& Boness D.J. 1985. Birth to weaning in 4 days: remarkable growth in the hooded seal, Cystophora cristata. Canadian Journal of Zoology 63, 2841-2842.

Bryden M.M. 1978. Arteriovenous anastomoses in the skin of seals. III. The harp seal Pagophilus groenlandicus and the hooded seal Cystophora cristata (Pinnipedia: phocidae). Aquatic Mammals 6, 67-75.

Carleton H.M. \& Drury R.A.H. 1957. Histological technique. London: Oxford University Press.

Carrick R., Csordas S.E., Ingham S.E. \& Keith K. 1962. Studies on the southern elephant seal, Mirounga leonina (L.). III. The annual cycle in relation to age and sex. CSIRO Wildlife Research 7, 119-160.

Carter H.B. \& Clarke W.H. 1957. The hair follicle group and skin follicle population of Australian merino sheep. Australian Journal of Agricultural Research 8, 91-108.

Chase H.B. 1954. Growth of the hair. Physiological Reviews 34, 113-126.

Erdsack N., Dehnhardt G., Witt M., Wree A., Siebert U. \& Hanke W. 2015. Unique fur and skin structure in harbour seals (Phoca vitulina)-thermal insulation, drag reduction, or both? Journal of the Royal Society Interface 12, article no. 20141206, doi: 10.1098/ rsif.2014.1206

Gurr G.T. 1969. Biological staining methods. Romford, UK: Baird \& Tatlock.

Hardy M.H. \& Lyne A.G. 1956. The pre-natal development of wool follicles in merino sheep. Australian Journal of Biological Science 9, 423-441.

Hardy M.H., Roff E., Smith T.G. \& Ryg M. 1991. Facial skin glands of ringed and gray seals and their possible function as odoriferous organs. Canadian Journal of Zoology 69, 189-200.

King J.E. 1966. Relationships of the hooded and elephant seals (genera Cystophora and Mirounga). Journal of Zoology, London 148, 385-398.

Kovacs K.M. 2009. Hooded seal Cystophora cristata. In W.F. Perrin et al. (eds.): Encyclopedia of marine mammals. 2nd edn. Pp. 569-573. New York: Academic Press.

Kovacs K.M. 2016. Cystophora cristata. The IUCN red list of threatened species. e.T6204A45225150. Accessed on the internet at 10.2305/IUCN.UK.2016-1.RLTS. T6204A45225150.en on 30 November 2017.

Kvadsheim P.H. \& Aarseth J.J. 2002. Thermal function of phocid seal hair. Marine Mammal Science 18, 952-962.

Ling J.K. 1965a. Hair growth and moulting in the southern elephant seal, Mirounga leonina (Linn.). In A.G. Lyne \&
B.F. Short (eds.): Biology of the skin and hair growth. Pp. 525-544. Sydney: Angus and Robertson.

Ling J.K. 1965b. Functional significance of sweat glands and sebaceous glands in seals. Nature 208, 560-562.

Ling J.K. 1968. The skin and hair of the southern elephant seal, Mirounga leonina (Linn.). III. Morphology of the adult integument. Australian Journal of Zoology 16, 629-645.

Ling J.K. 1970. Pelage and molting in wild mammals with special reference to aquatic forms. Quarterly Review of Biology 45, 16-54.

Ling J.K. 2013. The skin and hair of the southern elephant seal, Mirounga leonina (Linn.). IV. Annual cycle of pelage follicle activity and moult. Australian Journal of Zoology 60, 259-271.

Ling J.K. \& Bryden M.M. 1981. Southern elephant seal Mirounga leonina (Linnaeus), 1758. In S.H. Ridgway \& R.J. Harrison (eds.): Handbook of marine mammals. Vol. 2. Seals. Pp. 297-327. London: Academic Press.

Ling J.K. \& Button C.E. 1975. The skin and pelage of grey seal pups (Halichoerus grypus Fabricius): with a comparative study of foetal and neonatal moulting in the Pinnipedia. Rapports et Proces-Verbaux des Reunions Conseil International pour l'Exploration de la Mer 169, $112-132$.

Ling J.K. \& Thomas C.D.B. 1967. The skin and hair of the southern elephant seal. Mirounga leonina (Linn.). II. Pre-natal and early post-natal development and moulting. Australian Journal of Zoology 15, 349-365.

Lyne A.G. 1957. Bundles of primary wool follicles in sheep. Nature 179, 825-826.

Meyer W., Bollhorn M. \& Stede M. 2000. Aspects of general antimicrobial properties of skin secretions in the common seal Phoca vitulina. Diseases of Aquatic Organisms 41, 77-79.

Mohn M.P. 1958. The effects of different hormonal states on the growth of hair in rats. In W. Montagna \& R.A. Ellis (eds.): The biology of hair growth. Pp. 335-398. New York: Academic Press.

Mohr E. 1950. Behaarung und Haarwechsel der Robben. (Pelage and moulting in seals.) Neue Ergeb-Nisse und Problem per Zoologie (Klatt-Festschrift), Leipzig 145, 602-614.

Molyneux G.S. \& Bryden M.M. 1978. Arteriovenous anastomoses in the skin of seals. I. The Weddell seal Leptonychotes weddellii and the elephant seal Mirounga leonina (Pinnipedia: Phocidae). Anatomical Record 191, 239-252.

Montagna W. 1962. The structure and function of skin. 2nd edn. New York: Academic Press.

Montagna W. \& Harrison R.J. 1957. Specializations in the skin of the seal (Phoca vitulina). American Journal of Anatomy 100, 81-114.

Øigård T.A., Haug T. \& Nilssen K.T. 2014. Current status of hooded seals in the Greenland Sea. Victims of climate change and predation? Biological Conservation 172, 2936.

Øritsland T. 1964. Klappmysshunnens forplantnings - biologi. (The reproductive biology of the hooded seal female.) Fisken og Havet 1, 1-15.

Polkey W. \& Bonner W.N. 1966. The pelage of the Ross seal. British Antarctic Survey Journal 8, 93-96.

Rasmussen B. 1960. Om klapmyssbestanden in det nordlige Atlanter have. (On the stock of hooded seals in the northern Atlantic.) Fisken og Havet 1, 1-23. (Fisheries Research Board of Canada Translation Series 387, 1960.) 
Reeves R.R. \& Ling J.K. 1981. Hooded seal Cystophora cristata Erxleben, 1777. In S.H. Ridgway \& R.J. Harrison (eds.): Handbook of marine mammals. Vol. 2. Seals. Pp. 171-194. London: Academic Press.

Ronald K. \& Healy P.J. 1981. Harp seal Phoca groenlandica Erxleben, 1777. In S.H. Ridgway \& R.J. Harrison (eds.): Handbook of marine mammals. Vol. 2. Seals. 55-87. London: Academic Press.

Scheffer V.B. 1962. Pelage and surface topography of the northern fur seal. North American Fauna. Vol. 64. Washington D. C.: US Department of the Interior, Fish and Wildlife Service.
Scheffer V.B. 1964. Hair patterns in seals (Pinnipedia). Journal of Morphology 115, 291-304.

Sokolov V.E. 1958. The mechanics of heat dissipation in sea mammals. Bulletin of the Moscow Society of the Explorers of Nature 63, 5-12.

Temte J.L. 1985. Photoperiod and delayed implantation in the northern fur seal (Callorhinus ursinus). Journal of Reproduction and Fertility 73, 127-131.

Whittow G.C., Szekerczes J. \& Olsen D.L. 1975. Skin structure of the Hawaiian monk seal (Monachus schauinslandi). Pacific Science 29, 153-157. 